\title{
Endoscopic transluminal water irrigation for duodenal diverticulitis
}

Duodenal diverticula are usually asymptomatic, but complications such as cholestasis, inflammation, abscess formation, and perforation may occur, with clinically significant effects [1, 2]. In certain cases, endoscopic intervention may be chosen over surgery $[3,4]$. However, the former is a complicated procedure requiring careful manipulation of the endoscope.

A 75-year-old man presented with a high temperature of $38.5^{\circ} \mathrm{C}$ and pain in the right upper abdomen. Laboratory findings revealed notable inflammatory results, but with no elevation of liver enzymes or amylase level. A contrast-enhanced computed tomography (CT) scan showed a swollen juxtapapillary duodenal diverticulum containing air and fluid, and an increased concentration of surrounding fatty tissue ( $\triangleright$ Fig. 1). There was however no evidence of abscess formation or perforation. In spite of 2 days of fasting and the administration of broad-spectrum antibiotics, there was no clinical improvement, and resistance to conservative treatment was indicated in a subsequent endoscopic examination.

Side-viewing endoscopy revealed a juxtapapillary diverticulum impacted with food debris. Following disimpaction of the food debris using forceps, pus was discharged from the diverticulum ( $\triangleright$ Fig.2a,b). Thereafter, an endoscopic cannula was inserted on the underside of the diverticulum and plenty of water was delivered. A large amount of cylindrical food debris was released from the diverticulum around the cannula ( $\mathbf{F i g . 2 c}$; - Video 1). The endoscopic treatment was completed without placement of a drainage tube.

A subsequent diverticulogram revealed no residual food debris or perforation ( Fig.2d). The patient's clinical symptoms disappeared and laboratory findings returned to normal immediately after the procedure, which allowed early resumption of oral food intake. No fur-
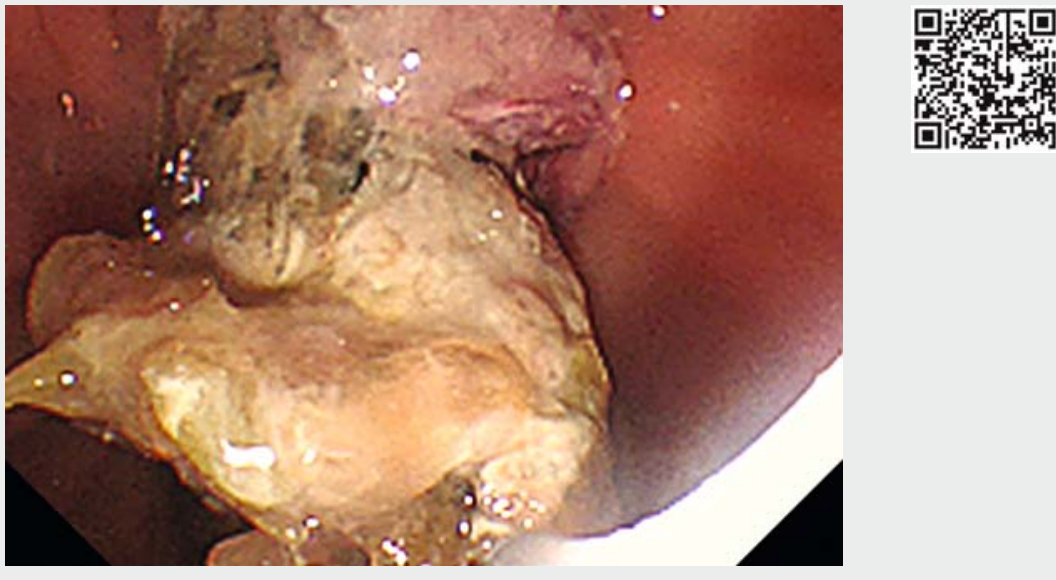

$\nabla$ Video 1 Disimpaction of food debris at the orifice of the diverticulum led to the discharge of pus. Thereafter, cannulation on the underside of the diverticulum and water irrigation released cylindrical food debris.

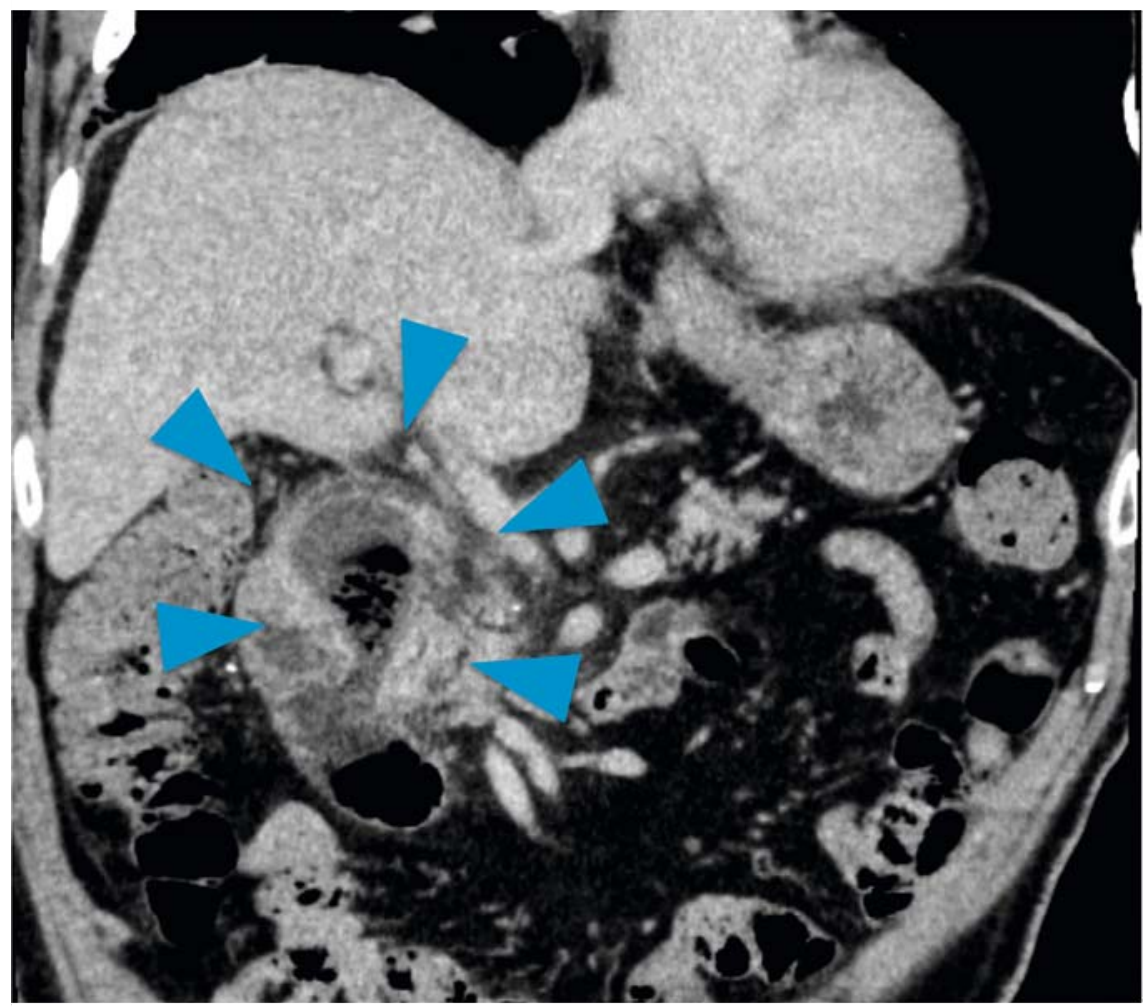

- Fig. 1 A 56×40-mm juxtapapillary duodenal diverticulum (blue arrowheads) containing food debris, with an increased concentration of surrounding fatty tissue. 

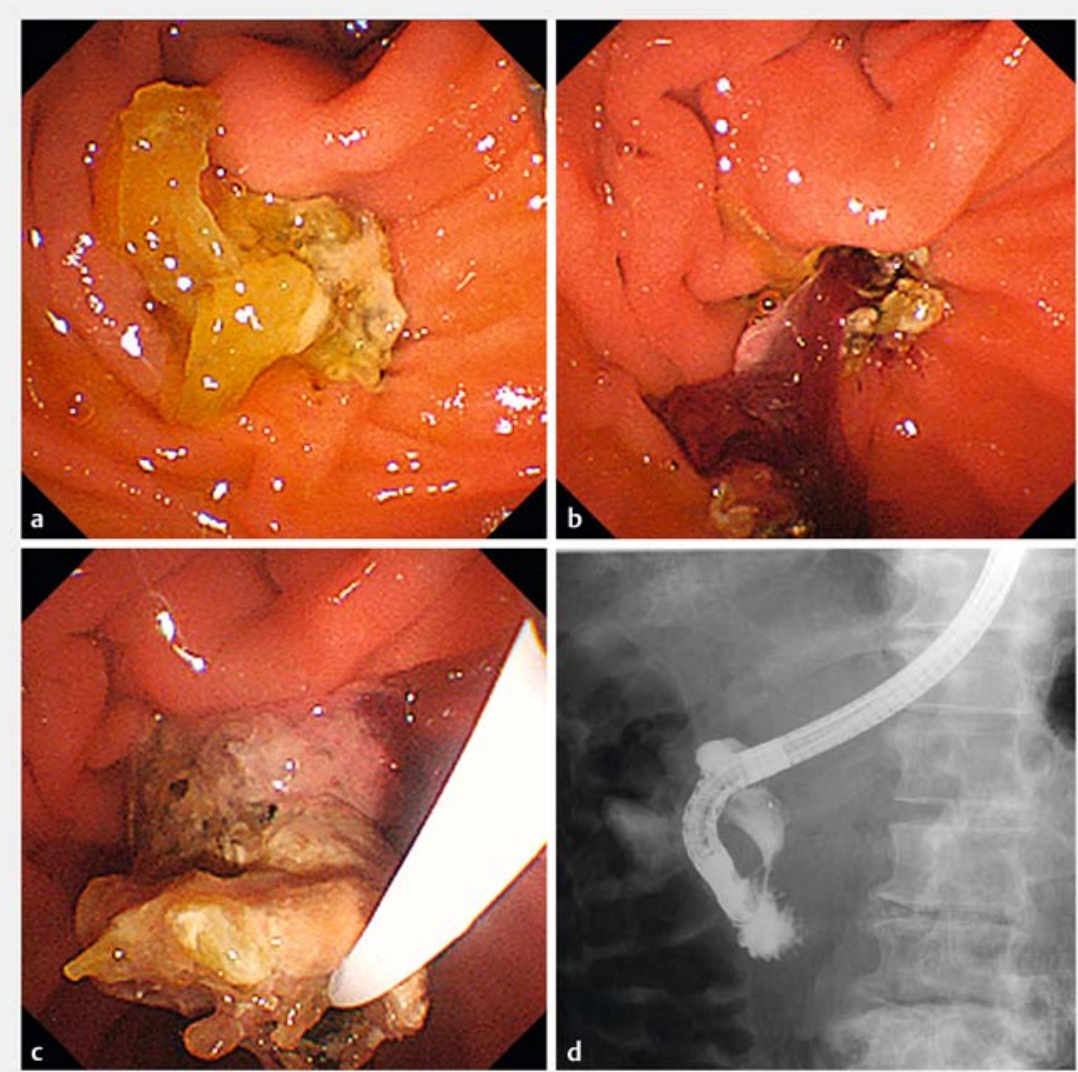

- Fig. 2 Endoscopic treatment of a duodenal diverticulum. a Food debris is seen impacted at the orifice of a juxtapapillary duodenal diverticulum. $\mathbf{b}$ Disimpaction of the food debris using forceps led to a discharge of pus from the diverticulum. c Large amounts of cylindrical food debris were released from the diverticulum during water irrigation through the endoscopic cannula. d A diverticulogram revealed no residual food debris and no findings suggestive of perforation.

ther clinical signs of exacerbation were observed within 3 months of discharge.

Placement of continuous drainage is considered unnecessary if the orifice is wide enough to allow the exodus of the content, unless abscess formation has been observed. In conclusion, endoscopic treatment may be a less complicated technique than surgical alternatives for treating duodenal diverticulitis, and it can be attempted before surgery in patients resistant to conservative treatment.

Endoscopy_UCTN_Code_TTT_1AO_2AD

Corresponding author

Taiki Aoyama, MD, PhD

Department of Gastroenterology, Hiroshima City Asa Citizens Hospital, 2-1-1 Kabeminami, Asakita-ku, Hiroshima 731-0293, Japan

Fax: +81-82-8141791

t-aoyama@asa-hosp.city.hiroshima.jp

\section{References}

[1] Caselitz M, Manns MP, Meier PN. Endoscopic management of duodenal diverticulitis causing common bile duct obstruction and cholangitis. Endoscopy 2002; 34: 591

[2] Ichikawa T, Koizumi J, Onoue K et al. CT features of juxtapapillary duodenal diverticula with complications. Tokai J Exp Clin Med 2008; 33: 90-94

[3] Tamura Y, Hayakawa M, Isogawa M et al. Duodenal diverticulitis accompanied by abscess formation treated successfully using an endoscopic nasobiliary drainage catheter: a case report. Clin J Gastroenterol 2017; 10: $240-243$

[4] Salah W, Harrion ME, Faigel DO et al. Acute duodenal diverticulitis treated with endoscopic therapy. Gastrointest Endosc 2014; 80: $522-523$

\section{Bibliography}

DOI https://doi.org/10.1055/a-0641-4898

Published online: 3.7.2018

Endoscopy 2018; 50: E274-E275

(c) Georg Thieme Verlag KG

Stuttgart · New York

ISSN 0013-726X

Competing interests

None

The authors

Taiki Aoyama ${ }^{1}$, Masanobu Yukutake ${ }^{1}$, Kenjiro Shigita ${ }^{2}$, Naoki Asayama ${ }^{1}$, Akira Fukumoto ${ }^{2}$, Shinichi Mukai ${ }^{1}$, Shinji Nagata ${ }^{1}$

1 Department of Gastroenterology, Hiroshima City Asa Citizens Hospital, Hiroshima, Japan

2 Department of Endoscopy, Hiroshima City Asa Citizens Hospital, Hiroshima, Japan

\section{ENDOSCOPY E-VIDEOS}

https://eref.thieme.de/e-videos

口回 Endoscopy E-Videos is a free 然部 靣解: on interesting cases and new techniques in gastroenterological endoscopy. All papers include a high quality video and all contributions are freely accessible online.

This section has its own submission website at https://mc.manuscriptcentral.com/e-videos 